\title{
Epidemiology of tendon and ligament injuries in Aotearoa/New Zealand between 2010 and 2016
}

Sita T. Clark', Mark Zhu ${ }^{1,2}$, Greg D. Gamble, Dorit Naot', Sarah-Jane Paine ${ }^{3}$, Nicola Dalbeth ${ }^{1,4}$, Jillian Cornish ${ }^{1}$ and David S. Musson ${ }^{1 *}$ (i)

\begin{abstract}
Background: Injuries to tendons and ligaments make up a large portion of musculoskeletal injuries, and contribute to significant morbidity and healthcare costs. However, there is currently a poor understanding of the burden of these injuries at a population level.

The purpose of this study was to quantify the burden and distribution of tendon and ligament injuries in the Aotearoa/New Zealand population.

Methods: Using the Accident Compensation Corporation (ACC, a no fault comprehensive compensation scheme encompassing all of Aotearoa/New Zealand; population in 20134.4 million) database, data specific to tendon and ligament injuries were identified between July 2010 and June 2016. The total number of claims made and the total cost of these claims per financial year were analyzed. Injuries were categorized by anatomical site, gender, ethnicity and age of the claimant.

Results: During the 6-year study period, the total number of tendon and ligament injury claims was 1,112,077, with a total cost of over $\$ 1.4$ billion NZD. There was a $16.2 \%$ increase in the number of claims, and a $40 \%$ increase in the total cost of these injuries during this period.

The majority of claims were made by people of European ethnicity, whilst the number of claims made by people of Asian ethnicity increased at the greatest rate; 52\% (from 9047 claims in 2011) during the 6-year study period. Interestingly, Māori (Indigenous New Zealanders) maintained the highest average cost per claim (\$1614.05 NZD); $13 \%$ more than the overall average cost per claim (\$1262.12 NZD). The most common sites of injury were the shoulder and knee; these injuries were also the greatest contributors to overall cost. The total costs of injuries peaked in claimants aged 40-54, irrespective of the number of claims made for that age group.

Conclusions: Health and economic burdens of tendon and ligament injuries in Aotearoa/New Zealand are rising. The high healthcare costs underscore the urgent need for multifaceted interventions to reduce the incidence and improve clinical outcomes of tendon and ligament injuries.
\end{abstract}

Keywords: Tendon, Ligament, Injuries, Epidemiology

\footnotetext{
* Correspondence: d.musson@auckland.ac.nz

${ }^{1}$ Department of Medicine, University of Auckland, Auckland, New Zealand

Full list of author information is available at the end of the article
}

(c) The Author(s). 2020 Open Access This article is distributed under the terms of the Creative Commons Attribution 4.0 International License (http://creativecommons.org/licenses/by/4.0/), which permits unrestricted use, distribution, and reproduction in any medium, provided you give appropriate credit to the original author(s) and the source, provide a link to the Creative Commons license, and indicate if changes were made. The Creative Commons Public Domain Dedication waiver (http://creativecommons.org/publicdomain/zero/1.0/) applies to the data made available in this article, unless otherwise stated. 


\section{Introduction}

Diseases and injuries of tendons and ligaments are some of the most commonly diagnosed musculoskeletal problems clinically (Clayton \& Court-Brown, 2008; James et al., 2008). In the United States, 33 million musculoskeletal injuries are reported each year, with nearly half of these involving tendons and ligaments (James et al., 2008). Although the majority of such injuries are nonfatal, they can be severely debilitating, resulting in significant reductions in patient quality of life, loss of productivity, and considerable costs to the healthcare system (Liu et al., 2008; Mock \& Cherian, 2008; Riley, 2008; Vitale et al., 2007). In the United Kingdom, absenteeism due to lateral epicondylitis (tennis elbow) alone, is approximated to cost $£ 27$ million per annum (WalkerBone et al., 2012). Furthermore, tendons and ligaments heal poorly frequently resulting in months of disability and weaker tendon(s) that are more susceptible to future injuries (Lipman et al., 2018; Riley, 2008). Despite our increased understanding of tendon biology and tendon repair mechanisms, we are yet to develop effective treatment strategies, and surgical outcomes are often poor (Coghlan et al., 2008; James et al., 2008; Kukkonen et al., 2014; Liu et al., 2008; Vitale et al., 2007).

The first step in a public health approach to injury prevention and treatment, is to define the magnitude of the problem and identify the epidemiological characteristics of the issue (Krug et al., 2000). To date, a number of studies have been undertaken in other countries to determine the incidence of specific tendon injuries, such as rotator cuff tears, Achilles ruptures and tears of the hip abductor (Albers et al., 2016; Colvin et al., 2012; De Boer et al., 2014; de Jong et al., 2014; Gianotti et al., 2009; Nyyssonen et al., 2008; Paloneva et al., 2015; Sanders Jr. et al., 2015; Zbrojkiewicz et al., 2018). From these, it is clear that the prevalence of specific tendon/ ligament injuries is rising, as is the cost of treating musculoskeletal disorders as a whole, with an aggregate total expenditure on musculoskeletal conditions increasing from US\$367.1 billion to $\$ 796.3$ billion, from 1996 to 1998 to 2009-2011 (Lipman et al., 2018). However, little work has been done to understand the burden of these injuries at the population-level, and no current data exists for Aotearoa/New Zealand (Hopkins et al., 2016). Here, we have undertaken an epidemiological study of tendon/ligament injuries to determine whether this global trend holds true in Aotearoa/New Zealand, and to identify epidemiological trends that can be used to build an informed healthcare approach to tackle this clinical problem at a national level.

We have used data sourced from the Aotearoa/New Zealand Accident Compensation Corporation System (ACC), Established in 1974, the ACC is a NZ government taxpayerfunded scheme which offers no fault compensation to every individual who suffers an accidental injury in Aotearoa/New Zealand (population according to the last Census in 2013 was $4,242,048)$, including overseas visitors. People who suffer an injury make a claim to ACC when seeking treatment from a medical professional. When making a claim, information is self-reported by the claimant using standard forms, with key demographic information recorded, including gender, self-reported ethnicity and age. The registered healthcare provider completes the form providing initial diagnosis and the claim is then filed with ACC. Once ACC has accepted a claim, compensation covers costs to the healthcare provider, medical treatment costs, surgery, income replacement (80\% of salary), rehabilitation (including work, home and vehicle modifications) and support services.

Being a no-fault compensation scheme, reporting of injuries is likely to be more comprehensive than in most other countries as there is no deterrent for making a claim. This places New Zealand in a unique position to provide detailed descriptive epidemiological data, including costs associated with treatment, which can be used for analysis.

Here, we have utilised this data set to determine the national burden of tendon and ligament injuries within Aotearoa/New Zealand, over a six-year period, and used this descriptive data to identify epidemiological trends.

\section{Methods}

This was a retrospective population-based study, investigating the nationwide epidemiology and burden of tendon and ligament injuries within Aotearoa/New Zealand, during a 6-year period from July 1st, 2010 through to June 30th, 2016.

Anonymized national claims data on tendon and ligament injuries were sourced from, and prepared by, the ACC. When a claim is lodged by a patient, a registered healthcare professional makes an initial diagnosis and assigns a Read code that most accurately matches the patient's injury. There are over 33,000 Read codes to choose from, so to isolate data specific to tendon and ligament injuries the search terms "Tendon, Tendonitis, Tenosynovitis, Ligament, Epicondylitis and Rotator Cuff" were used to identify relevant Read codes. This produced information from 511 Read codes, which were considered relevant to this study (Additional file 1). We obtained data on the number of claims made for these injuries per year from July 1st to June 30th (total Claim Count) and the costs that these claims accrued over time Cost Ex GST in New Zealand Dollars (NZD)).

Injuries were categorised based on anatomical site of the injury (Shoulder, Elbow, Knee, Ankle, Finger, Thumb \& Wrist, Upper \& Lower Arm, and Hip, Upper Leg \& Thigh). These were then divided into subgroups based on gender (Male and Female), ethnicity (classified as either Māori (the indigenous people), Pacific Peoples, Asian, 
"Other" ethnicity, and European, using the prioritisation system developed for the NZ health and disability sector (MinistryofHealth, 2017)), and age band at lodgement of claim (0-14 years, 15-19 years, 20-24 years, 25-29 years, 30-34 years, 35-39 years, 40-44 years, 45-49 years, 5054 years, 55-59 years, 60-64 years, 65-69 years, 70-74 years, $75-79$ years, $80-84$ years, 85 years and over).

The total number and total cost of claims were produced by ethnicity, age-group and gender. Age-ethnicity specific population estimates from the 2013 NZ Census, sourced from Statistics NZ, served as denominators for the calculation of the age-specific rates for each ethnic group in that year. Rates (with 95\% confidence intervals) are reported per 100,000 people.

Specific cost per claim values were calculated (Cost excluding GST divided by the number of claims (Claim Count)). Predicted values for the year 2030 were extrapolated from 6 year data (2011 to 2016) using ordinary least squares (OLS) regression, performed using Prism (Prism version 8.0.0 for Windows, GraphPad Software, San Diego, California USA, www. graphpad.com). All costs are shown in New Zealand Dollars.

\section{Results}

The burden of tendon/ligament injuries is increasing.

During the study period, the total number of tendon and ligament injury claims accepted by ACC was $1,112,077$, and the cost of these claims totaled over $\$ 1.4$ billion NZD. Annually, the number of claims increased from 170,874 in 2011 , to 198,580 in 2016 (a total increase of $16 \%)$. There was also a rise in the total annual cost ex GST for the claims, from $\$ 202,526,476$ to $\$ 283,334,932$ (a total increase of 40\%), and cost per claim, from $\$ 1185.24$ to $\$ 1426.80$ (a total increase of 20\%) between 2011 to 2016 (Table 1 ).

Using the data collected in this study, OLS regression was performed to predict the future burden of tendon injuries. If a linear increase in these claims were to occur, by the year 2030 the total number of claims per year will increase to 274,786; a 38\% increase from 2016. Furthermore, the total annual cost ex GST will rise to approximately $\$ 518,500,000$ (an 83\% increase from 2016), and the average cost per claim will increase $52 \%$ to $\$ 2169.48$ (Fig. 1).
There is a gender disparity in the number and cost of claims made for tendon/ligament injuries

Over the 6-year period reviewed here, there were consistently more claims made by males than females, with males accounting for $56 \%$ of all claims made for tendon and ligament injuries (Table 2). According to the 2013 Aotearoa/New Zealand Census, females and males comprised 51.3 and $48.7 \%$ of the Aotearoa/New Zealand population, respectively (Additional file 1), suggesting an over-representation of claims made by males.

The total cost of claims made by males was also higher than females, comprising $69 \%$ of the total cost of claims over the 6 years, and totalling over $\$ 966$ million NZD, compared to the total cost of $\$ 437$ million NZD for females. As a result, the cost per claim for males averaged at $\$ 1549.15$ over the 6-year period; substantially higher than the female cost per claim, which averaged at $\$ 887.76$ (Table 2).

When we considered specific injury sites, males represented the largest proportion of claims for all sites, except for injuries to the tendons of the finger, thumb and wrist, where females represented $52 \%$ of all claims made over the 6-year period (Additional file 1).

\section{Asian people have had the highest rate of increase in number of claims and Māori maintain the highest cost per claim for tendon/ligament injuries}

Over the 6 year study period, people of European ethnicity made up $71 \%$ of all claims made, whilst Māori comprised $11.0 \%$, Asian 6\%, Pacific peoples 6\%, and "Other" ethnicity $6 \%$. This is compared to Aotearoa/New Zealand 2013 Census prioritised ethnicity population figures of $63.7 \%$ for European, $15.6 \%$ for Māori, $11.7 \%$ for Asian, 6.4\% for Pacific peoples, 2.5\% for "Other" ethnicity (Additional file 1).

This suggests that the total number of claims made by European and "Other" ethnicities were high, relative to their population proportion (over-represented), whilst claims made by Asian and Māori people were low, relative to their population proportion (under-represented). Despite this, the number of claims made by people of Asian ethnicity increased $52 \%$ during the 6 year study period (9047 in 2011 to 13,750 in 2016), and 22\% by Māori (18, 254 in 2011 to 22,187 in 2016). This was a larger rate of increase compared to the $16 \%$ elevation in claims overall.

Table 1 Annual total claim count, total cost and cost per claim for each year within the 6-year study period. All costs are shown in New Zealand Dollars

\begin{tabular}{llllllll}
\hline End of reporting year & 2011 & 2012 & 2013 & 2014 & 2015 & 2016 & 6 Year Total \\
\hline Total Claim Count & 170,874 & 178,902 & 183,385 & 184,863 & 195,473 & 198,580 & $1,112,077$ \\
Total Cost Ex GST & $\$ 202,526,476$ & $\$ 203,975,934$ & $\$ 215,716,748$ & $\$ 233,429,167$ & $\$ 264,591,232$ & $\$ 283,334,932$ & $\$ 1,403,574,489$ \\
Average Cost per Claim & $\$ 1,185.24$ & $\$ 1,140.15$ & $\$ 1,176.31$ & $\$ 1,262.71$ & $\$ 1,353.59$ & $\$ 1,426.80$ & $\$ 1,262.12$ \\
\hline
\end{tabular}



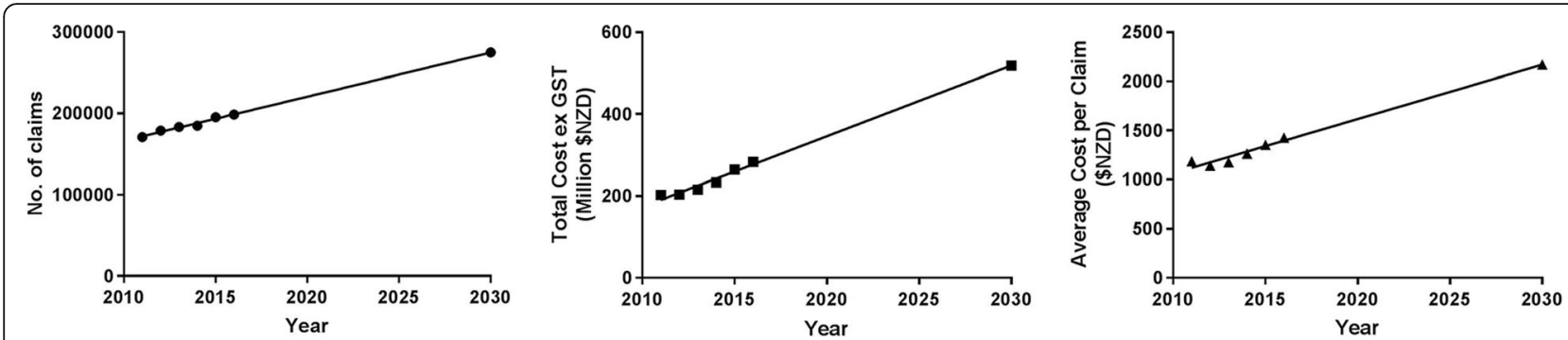

Fig. 1 Future predicted trends in tendon and ligament injuries using study data after performing OLS regression. a Claim count b Cost Ex GST and $\mathbf{c}$ Average cost per claim

In comparison, there was a $13 \%$ increase in claims by people of European ethnicity, 12\% by Pacific Peoples, and $19 \%$ by the "Other" ethnic grouping.

Māori had the highest average cost per claim during the 6 year study period, relative to all other ethnicity groups. In 2016, the average cost per claim for Māori was \$1614.05. This was $13 \%$ more than the average cost per claim that year, $10 \%$ more than the average cost per claim of \$1472.11 for people of European ethnicity, and 70\% more than the $\$ 949.42$ for people of Asian ethnicity (Table 3).

Tendon injuries in the shoulder were the most commonly claimed injury site for all ethnic groups except Māori, where the knee was the most common claim site (Additional file 1).

In an attempt to better understand the ethnic differences within our population, we estimated the age-specific rates for each ethnic group during the census year 2013 using their unique population size as the denominator (Fig. 2).

The "Other" ethnic group had the highest rate and cost of claims of all the ethnic groups. In the younger age groups ( $<40$ yrs. of age), Pacific Peoples had higher rates of claims than European and Māori, while Asian people had the lowest rate of claims. In the 20-24 age group, for example, the age specific rates per 100,000 people were 12,162 for the "Other" ethnic group, 7062 for Pacific Peoples, 5417 for European people, 3970 for Māori, and 1743 for Asian people. In contrast, European people had higher rates of claims and costs of claims at ages $\geq 40 y$, with
Māori, Pacific and Asian people having similar rates. In the 50-54 age group, "Other" ethnicities still had the highest rate of claims, at 9906/100,000 people, followed by Europeans with 5947/100,000 people, Māori with 4037/100, 000 people, Pacific Peoples 3689/100,000 people, and Asian people 3299/100,000 people.

\section{Injuries to the shoulder and knee account for the majority of tendon/ligament injuries}

Two anatomical sites where injuries occurred more commonly, and had higher costs, were the shoulder and knee. Shoulder injuries accounted for $33 \%$ of all claims made over the 6 year period, and $40.6 \%$ of all costs, whilst knee injuries accounted for $25 \%$ of all claims and $30 \%$ of the total cost of all tendon and ligament injuries during this period.

The number of claims at all sites increased substantially over the 6 years, except for tendon and ligament injuries involving the knee. Knee injuries only increased $5 \%$ over the 6-year period, which was minor compared to the overall increase of total claims, which was $16.2 \%$ during this time period (Table 4).

\section{Cost of claims for injuries to all anatomical sites are higher for claimants in their middle years}

The age distribution of claims varied considerably by anatomical site (Fig. 3). Claims made for injuries to the

Table 2 Annual total claim count, total cost ex GST and cost per claim per gender for each year, within the 6 year study period

\begin{tabular}{|c|c|c|c|c|c|c|c|}
\hline End of reporting year & 2011 & 2012 & 2013 & 2014 & 2015 & 2016 & 6 Year Total \\
\hline \multicolumn{8}{|l|}{ Total Claim Count } \\
\hline Females & 73,924 & 77,618 & 80,214 & 81,712 & 87,002 & 89,569 & 490,039 \\
\hline Males & 96,950 & 101,284 & 103,171 & 103,151 & 108,471 & 109,011 & 622,038 \\
\hline \multicolumn{8}{|l|}{ Total Cost } \\
\hline Females & $\$ 61,342,029$ & $\$ 62,496,249$ & $\$ 67,973,231$ & $\$ 73,495,812$ & $\$ 83,134,428$ & $\$ 88,599,765$ & $\$ 437,041,514$ \\
\hline Males & $\$ 141,184,447$ & $\$ 141,479,685$ & $\$ 147,743,517$ & $\$ 159,933,355$ & $\$ 181,456,804$ & $\$ 194,735,167$ & $\$ 966,532,975$ \\
\hline \multicolumn{8}{|l|}{ Average Cost per Claim } \\
\hline Females & $\$ 829.80$ & $\$ 805.18$ & $\$ 847.40$ & $\$ 899.45$ & $\$ 955.55$ & $\$ 989.18$ & $\$ 887.76$ \\
\hline Males & $\$ 1,456.26$ & $\$ 1,396.86$ & $\$ 1,432.03$ & $\$ 1,550.48$ & $\$ 1,672.86$ & $\$ 1,786.38$ & $\$ 1,549.15$ \\
\hline
\end{tabular}


Table 3 Annual total claim count, total cost and cost per claim for each ethnicity per year within the 6 year study period

\begin{tabular}{|c|c|c|c|c|c|c|c|}
\hline End of reporting year & 2011 & 2012 & 2013 & 2014 & 2015 & 2016 & 6 Year Total \\
\hline \multicolumn{8}{|l|}{ Total Claim Count } \\
\hline Asian & 9047 & 9793 & 10801 & 11466 & 12694 & 13750 & 67,551 \\
\hline European & 123187 & 128439 & 130469 & 130970 & 137725 & 139036 & 789,826 \\
\hline Māori & 18254 & 19422 & 20195 & 20344 & 21636 & 22187 & 122,038 \\
\hline Pacific Peoples & 10436 & 11063 & 11480 & 11419 & 11833 & 11694 & 67,925 \\
\hline Other & 9950 & 10185 & 10440 & 10664 & 11585 & 11913 & 64,737 \\
\hline \multicolumn{8}{|l|}{ Total Cost } \\
\hline Asian & $\$ 6,951,815$ & $\$ 8,212,380$ & $\$ 8,514,828$ & $\$ 10,037,482$ & $\$ 12,233,927$ & $\$ 13,054,593$ & $\$ 59,005,025$ \\
\hline European & $\$ 149,149,851$ & $\$ 151,579,282$ & $\$ 158,871,869$ & $\$ 171,371,660$ & $\$ 193,023,911$ & $\$ 204,676,415$ & $\$ 1,028,672,988$ \\
\hline Māori & $\$ 25,676,323$ & $\$ 23,906,838$ & $\$ 26,032,065$ & $\$ 28,234,531$ & $\$ 33,027,049$ & $\$ 35,811,028$ & $\$ 172,687,834$ \\
\hline Pacific Peoples & $\$ 10,133,189$ & $\$ 9,938,416$ & $\$ 10,867,981$ & $\$ 12,171,085$ & $\$ 12,970,137$ & $\$ 14,957,285$ & $\$ 71,038,093$ \\
\hline Other & $\$ 10,615,297$ & $\$ 10,339,019$ & $\$ 11,430,002$ & $\$ 11,614,411$ & $\$ 13,336,207$ & $\$ 14,835,612$ & $\$ 72,170,548$ \\
\hline \multicolumn{8}{|l|}{ Average Cost per Claim } \\
\hline Asian & $\$ 768.41$ & $\$ 838.60$ & $\$ 788.34$ & $\$ 875.41$ & $\$ 963.76$ & $\$ 949.42$ & $\$ 863.99$ \\
\hline European & $\$ 1,210.76$ & $\$ 1,180.17$ & $\$ 1,217.70$ & $\$ 1,308.48$ & $\$ 1,401.52$ & $\$ 1,472.11$ & $\$ 1,298.46$ \\
\hline Māori & $\$ 1,406.61$ & $\$ 1,230.92$ & $\$ 1,289.04$ & $\$ 1,387.86$ & $\$ 1,526.49$ & $\$ 1,614.05$ & $\$ 1,409.16$ \\
\hline Pacific Peoples & $\$ 970.98$ & $\$ 898.35$ & $\$ 946.69$ & $\$ 1,065.86$ & $\$ 1,096.10$ & $\$ 1,279.06$ & $\$ 1,042.84$ \\
\hline Other & $\$ 1,066.86$ & $\$ 1,015.12$ & $\$ 1,094.83$ & $\$ 1,089.12$ & $\$ 1,151.16$ & $\$ 1,245.33$ & $\$ 1,114.83$ \\
\hline
\end{tabular}

shoulder and upper \& lower arm peaked between the ages of 45 and 54. Injuries at the finger, thumb \& wrist, hip, upper leg \& thigh, and knee appeared to be more common in younger individuals, peaking between the ages of 0 and 19. In comparison, tendon injuries involving the elbow and the ankle showed a bimodal age distribution. Both anatomical sites peak in claims in early life (0-14 years) and peak again in the middle aged population (40-49 years).

When looking at the cost of claims, nearly all injuries cost more for claimants aged 40-54 years, irrespective of the age distribution of the number of claims made, with shoulder injuries making up over half of the costs for these age groups. The exception were tendon injuries of the knee, which peaked in cost between the ages of 20 and 24 (Fig. 3).

\section{Discussion}

This is the first study to demonstrate a rise in tendon and ligament injuries in Aotearoa/New Zealand, both in number of claims and in financial burden at a national level. Furthermore, it, and has identified key epidemiological trends in injuries across different ethnic groups, anatomical sites and age groups. The staggering 1,112,077 claims, at a cost of over \$1.4 billion NZD during this study period, in a country with a population of 4,242,048 (2013 census data), clearly highlights these injuries as a significant burden to the Aotearoa/New Zealand healthcare system. To put this into context, during our study period healthcare spending in Aotearoa/New Zealand increased from \$13.13 billion NZD in 2010 to $\$ 15.63$ billion NZD, an increase of
$13 \%$. The costs associated with injuries to tendons and ligaments, however, increased by $40 \%$, suggesting that these injuries are increasing in their burden on the Aotearoa/ New Zealand healthcare system.

The increasing numbers and costs of specific tendon injuries have been previously highlighted in a number of studies (Clayton \& Court-Brown, 2008; Colvin et al., 2012; Paloneva et al., 2015; Sanders Jr. et al., 2015). In contrast, other studies have suggested decreasing rates, specifically of hand and wrist injuries in one region of the United States (de Jong et al., 2014), as well as decreased tendon and ligament injuries of the foot and ankle presenting to emergency departments in the Netherlands (De Boer et al., 2014). Our study found an overall increase in reported tendon and ligament injuries, and although we do not have data on specific injuries, we have identified that these increases in the number and cost of injuries were present for all anatomical sites, including the hand/wrist and the foot/ankle.

The most commonly injured anatomical sites in our study were the shoulder, knee, and finger/hand/wrist, which comprised 33, 25 and 19\% of all claims, respectively. In an epidemiological study of 2794 patients presenting to the Orthopaedic Trauma Unit in the Royal Infirmary of Edinburgh over a 5-yr period, meniscal injury of the knee was the most common form of musculoskeletal injury, followed by injuries to the hand extensor tendons and the acromioclavicular joint (Clayton \& Court-Brown, 2008) These injuries are also likely to be contributing to our claims, as are rotator cuff and ACL tears, with rotator cuff repairs increasing 141\% from 1996 to 2006 in the US, and 


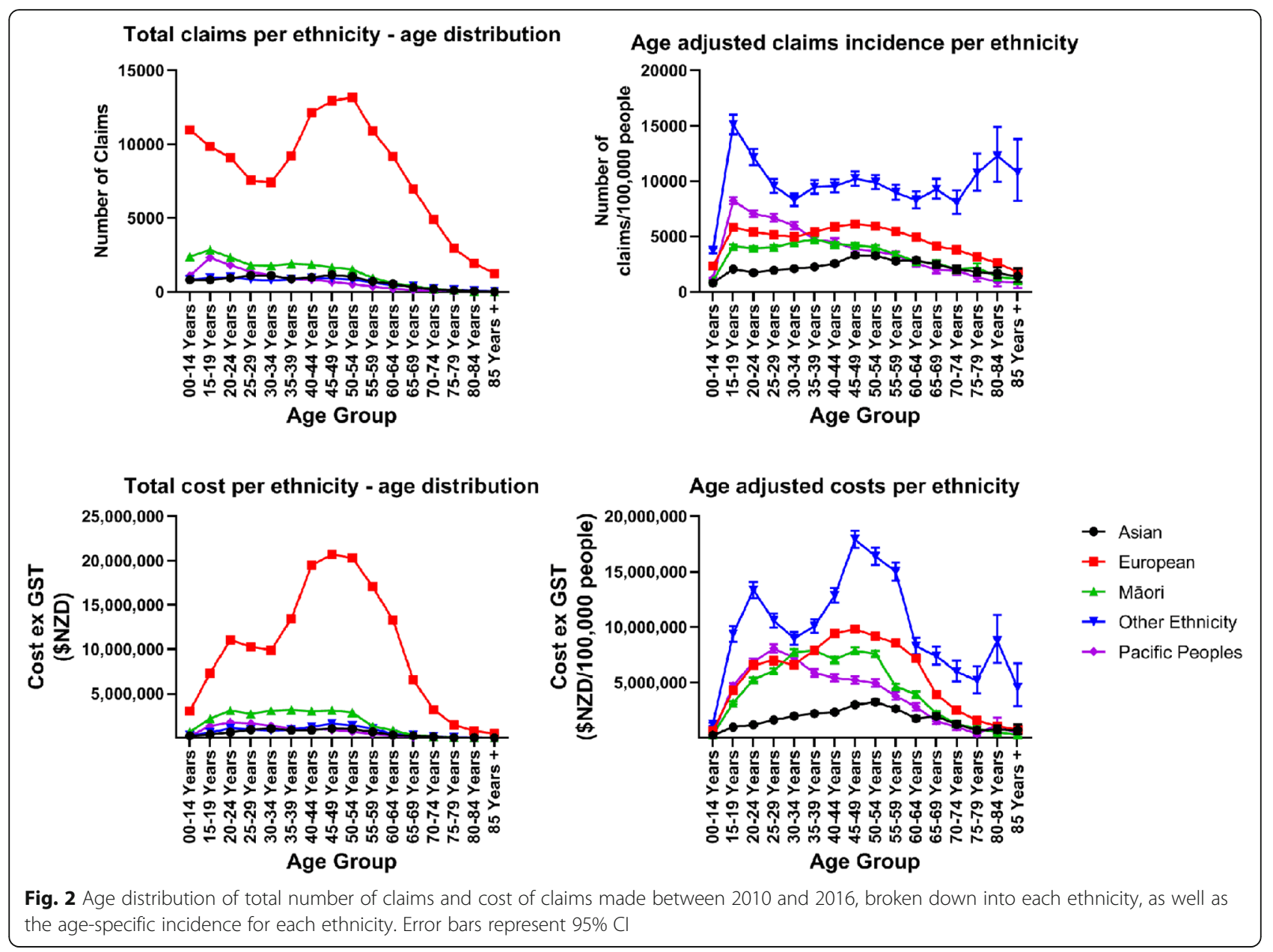

increasing 204\% from 1998 to 2011 in Finland (Colvin et al., 2012; Paloneva et al., 2015). A recent study in Australia has observed a 143\% increase in ACL reconstructions between 2000 and 2015 (Zbrojkiewicz et al., 2018).

Interestingly, injuries to the shoulder were the most common claim made during our study period for all ethnic groups, other than Māori, for whom knee injuries were more common. Whilst the exact reason for this is unknown, a recent study suggested that Māori were underrepresented in the number of rotator cuff repairs performed across Aotearoa/New Zealand between March 2009 and December 2010, and that Māori patients who did undergo rotator cuff repair presented younger, with more pain and poorer function than other ethnicities (Maher et al., 2017). The present analysis provides an important addition to the evidence by demonstrating ethnic disparities in the rate and cost of claims made for tendon and ligament injuries. Using the European group as a reference, Pacific peoples had higher claim rates until age 35y, after which Pacific claim rates were lower than those for the European ethnic group. In contrast, Māori and Asian people showed lower claim rates compared with Europeans at every age-group. The age-specific costs of claims for each ethnic group also highlight some interesting patterns, with the cost of claims being similar for Māori, European and Pacific people all showing similar costs up until age $35 y$, at which point the costs appear to diverge, with European injury claims being the highest and Pacific injury claims having the lowest costs. Meanwhile, the "Other" ethnic grouping had the highest rate of claims and costs at every age-group in this study. It is possible that the estimates for this ethnic grouping are influenced by the low number of claims for this ethnic grouping, and by the differences in the definition used to create the "Other" ethnic grouping between ACC and Statistics NZ. Notwithstanding these potential limitations, this study and others suggests that ethnic inequities in tendon and ligament injuries exist in New Zealand. Although the study was not designed to identify the determinants of these inequities, they likely reflect a range of factors, including age-related differences in the type and severity of injuries, as seen in the aforementioned rotator cuff study (Maher et al., 2017), and barriers to accessing primary care referrals to ACC provider (Jansen et al., 2008). As ACC costs also include covering a 
Table 4 Annual total claim count, total cost and cost per claim for each anatomical injury site per year within the 6 year study period

\begin{tabular}{|c|c|c|c|c|c|c|c|}
\hline End of reporting year & 2011 & 2012 & 2013 & 2014 & 2015 & 2016 & 6 Year Totals \\
\hline \multicolumn{8}{|l|}{ Total Claim Count } \\
\hline Shoulder & 57,586 & 60,520 & 60,942 & 62,727 & 65,235 & 64,883 & 371,893 \\
\hline Elbow & 4,577 & 5,047 & 6,027 & 6,071 & 6,236 & 5,744 & 33,702 \\
\hline Knee & 45,983 & 47,971 & 47,522 & 44,339 & 47,313 & 48,402 & 281,530 \\
\hline Ankle & 16,851 & 16,978 & 18,465 & 19,045 & 20,179 & 20,257 & 111,775 \\
\hline Finger, Thumb and Wrist & 31,788 & 33,333 & 33,889 & 35,850 & 37,904 & 40,034 & 212,798 \\
\hline Upper and Lower Arm & 1,087 & 1,168 & 1,282 & 1,374 & 1,615 & 1,614 & 8,140 \\
\hline Hip, Upper Leg and Thigh & 13,002 & 13,885 & 15,258 & 15,457 & 16,991 & 17,646 & 92,239 \\
\hline \multicolumn{8}{|l|}{ Total Cost } \\
\hline Shoulder & $\$ 83,024,989$ & $\$ 84,488,617$ & $\$ 84,022,261$ & $\$ 95,387,639$ & $\$ 108,755,719$ & $\$ 113,599,314$ & $\$ 569,278,539$ \\
\hline Elbow & $\$ 3,898,729$ & $\$ 3,927,779$ & $\$ 4,649,262$ & $\$ 5,253,332$ & $\$ 6,559,852$ & $\$ 7,127,880$ & $\$ 31,416,834$ \\
\hline Knee & $\$ 63,619,190$ & $\$ 63,520,525$ & $\$ 68,996,408$ & $\$ 69,660,313$ & $\$ 75,909,954$ & $\$ 81,310,524$ & $\$ 423,016,914$ \\
\hline Ankle & $\$ 17,253,990$ & $\$ 16,826,440$ & $\$ 19,527,548$ & $\$ 21,029,682$ & $\$ 24,043,240$ & $\$ 25,618,025$ & $\$ 124,298,925$ \\
\hline Finger, Thumb and Wrist & $\$ 24,778,763$ & $\$ 24,690,955$ & $\$ 26,606,154$ & $\$ 29,293,309$ & $\$ 34,085,529$ & $\$ 38,107,113$ & $\$ 177,561,823$ \\
\hline Upper and Lower Arm & $\$ 4,249,063$ & $\$ 4,665,164$ & $\$ 4,918,263$ & $\$ 5,175,319$ & $\$ 6,241,071$ & $\$ 7,414,596$ & $\$ 32,663,476$ \\
\hline Hip, Upper Leg and Thigh & $\$ 5,701,752$ & $\$ 5,856,454$ & $\$ 6,996,852$ & $\$ 7,629,573$ & $\$ 8,995,867$ & $\$ 10,157,480$ & $\$ 45,337,978$ \\
\hline \multicolumn{8}{|l|}{ Average Cost per Claim } \\
\hline Shoulder & $\$ 1,442.00$ & $\$ 1,396.00$ & $\$ 1,379.00$ & $\$ 1,521.00$ & $\$ 1,667.00$ & $\$ 1,751.00$ & $\$ 1,526.00$ \\
\hline Elbow & $\$ 851.81$ & $\$ 778.24$ & $\$ 771.41$ & $\$ 865.32$ & $\$ 1,051.93$ & $\$ 1,240.93$ & $\$ 926.61$ \\
\hline Knee & $\$ 1,383.54$ & $\$ 1,324.14$ & $\$ 1,451.88$ & $\$ 1,571.08$ & $\$ 1,604.42$ & $\$ 1,679.90$ & $\$ 1,502.49$ \\
\hline Ankle & $\$ 1,023.91$ & $\$ 991.07$ & $\$ 1,057.54$ & $\$ 1,104.21$ & $\$ 1,191.50$ & $\$ 1,264.65$ & $\$ 1,105.48$ \\
\hline Finger, Thumb and Wrist & $\$ 779.50$ & $\$ 740.74$ & $\$ 785.10$ & $\$ 817.11$ & $\$ 899.26$ & $\$ 951.87$ & $\$ 828.93$ \\
\hline Upper and Lower Arm & $\$ 3,908.98$ & $\$ 3,994.15$ & $\$ 3,836.40$ & $\$ 3,766.61$ & $\$ 3,864.44$ & $\$ 4,593.93$ & $\$ 3,994.09$ \\
\hline Hip, Upper Leg and Thigh & $\$ 438.53$ & $\$ 421.78$ & $\$ 458.57$ & $\$ 493.60$ & $\$ 529.45$ & $\$ 575.63$ & $\$ 486.26$ \\
\hline
\end{tabular}

component of the patient's salary during recovery, the higher unemployment rates and lower wages for Māori and Pacific people will also influence the costs associated with injuries in this study.

This analysis has shown that the majority of claims occur during the early years of life (0-19), or during the middle years of life (40-54). Most previous studies looking at specific tendon injuries have observed similar age-related trends (De Boer et al., 2014; de Jong et al., 2014; Gianotti et al., 2009; Houshian et al., 1998; Nyyssonen et al., 2008; Sanders Jr. et al., 2015), the hypothesis being that early injuries are more likely due to sporting injuries and active extracurricular activities, whilst later injuries are more likely to involve a degree of tendon degeneration, predisposing them to injury. Importantly, the highest costs were seen for those in the 40-54 age group. This is the first study to show this trend, and suggests that tendon injuries with a degenerative aspect may be a greater burden to healthcare systems.

This study used certain search terms in an attempt to cover all ACC claims involving tendon and ligament injuries. However, an ACC claim is conditional on the practitioner determining the injury as being caused by an accident, and correctly categorising the injury. Therefore, a limitation of this study is that data encompassing purely degenerative cases of tendon and ligament damage would not be reported, which would result in an underestimation of the true burden. Similarly, if injuries are not be catagorised correctly, this would also underestimate the overall burden. Further problems with this system of reporting and claims come from information bias when a patient self-reports their injury, as issues surrounding recall bias, and accuracy of self-reported information arise.

ACC allow for multiple claims to be made by an individual for one injury, and includes claims made by overseas visitors to Aotearoa/New Zealand. Therefore, injury rates based on ACC claims could overestimate the incidence of injuries during this time-period. To circumvent this, we have calculated direct age-adjusted rates for the year 2013 only, which was when the last census was performed. Census data include all persons in Aotearoa/New Zealand on that day, and thus includes overseas visitors, which gives us the most accurate estimation available.

Using these data to calculate age-adjusted rates for each ethnicity also allows for a more accurate comparison between populations. The New Zealand healthcare 


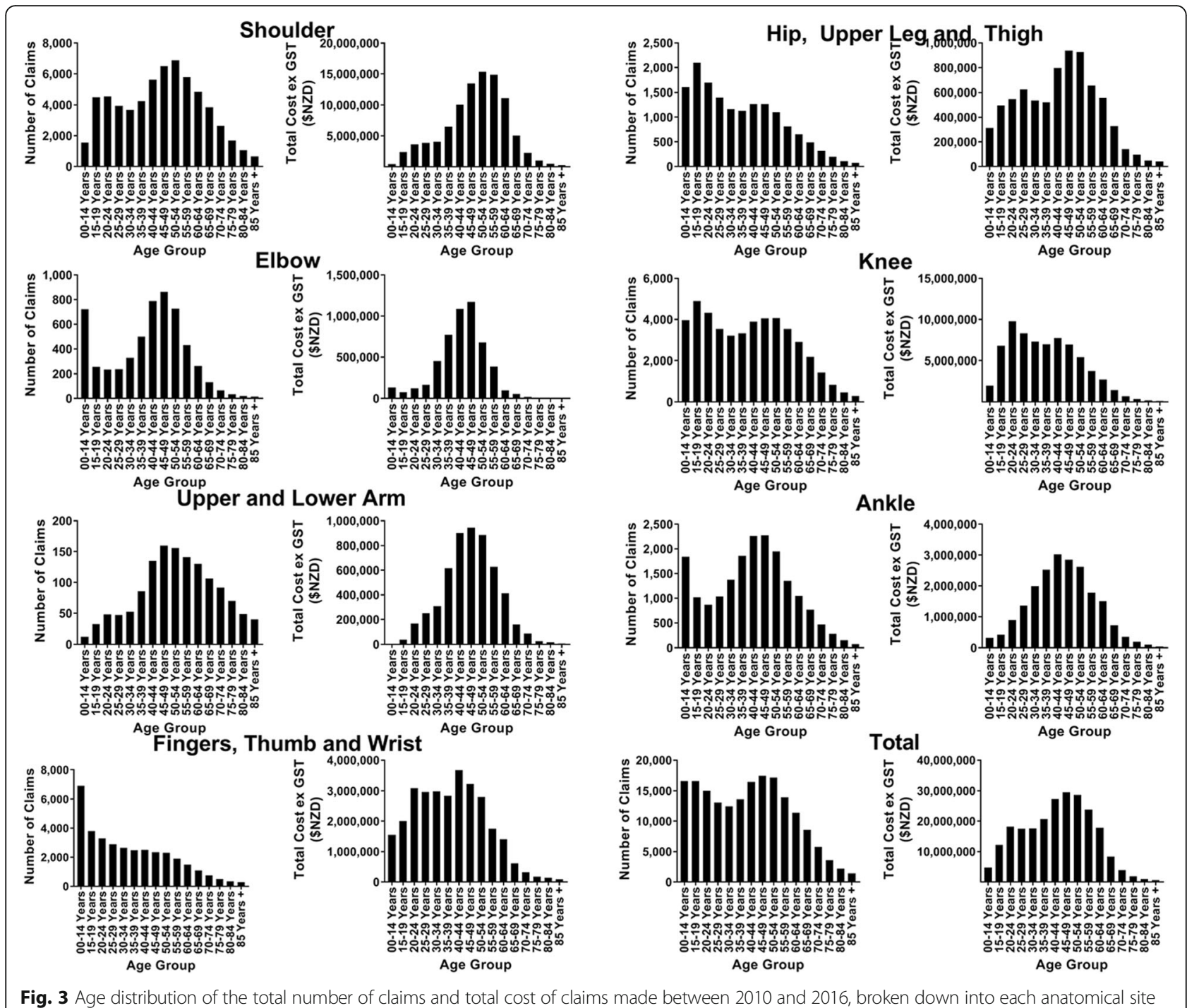

system reports prioritized ethnicity, where despite each person being able to identify with multiple ethnicities, the responses are categorized for output in prioritized order (MinistryofHealth, 2017), and this is how ACC report their data also. New Zealand prioritized ethnicity population data, however, is only available during census years and is provided by Stats NZ. Ethnicity may be entered and recorded differently in these databases, and therefore numerator/denominator bias may have been introduced into our estimates. As such, future studies investigating the collection and reporting quality of ethnicity data would be of benefit.

In order to explore our results further, and truly understand the health and socio-economic burden of tendon and ligament injuries, future studies should focus on the prevalence and cost of specific tendon and ligament injury diagnoses, by age group, ethnicity and socioeconomic deprivation, and to calculate rates using specific population denominators similar to the age-adjusted rates reported in Fig. 2. This will help fully characterize the burden of these injuries, identify at risk populations, and tailor intervention and treatments accordingly. Unfortunately, that was not possible within this study due to the anonymized nature of the data we received from ACC and the methods by which they record ethnicities.

A major strength of this study is that it is the first of its kind to demonstrate the burden of all tendon injuries at a national level. Furthermore, it provides a clear insight into how these debilitating injuries are increasing in number and cost, and which injuries and population groups are more likely to be affected. Most published studies on tendon injuries are limited to a smaller sample size and/or a shorter study duration (Albers et al., 2016; Clayton \& Court-Brown, 2008; de Jong et al., 2014; Gianotti et al., 2009; Houshian et al., 1998; Nyyssonen et al., 2008; Paloneva et al., 2015; Raikin et al., 2013). However, this study includes data from 
over 1.1 million claims over a 6 year period, and ACC's nationwide data collection means we can accumulate comprehensive information regarding the burden of tendon and ligament injuries at a nationwide level. Current reports also suggest that two thirds of tendon and ligament injury cases are not reported (Hopkins et al., 2016), and it is true that this study will also be missing some data due to lack of reporting. However, as ACC offers a "no fault" compensation scheme, reporting of injuries is likely to be more comprehensive than in most other countries.

\section{Conclusion}

Overall, this study has highlighted the increasing number and cost of tendon injuries across Aotearoa/New Zealand; a trend that is likely similar globally. Whilst the data reported here is broad in it's inclusion, it is hopeful that this can be used as a starting point for framing future studies which more specifically address the growing burden of tendon and ligament injuries. It is difficult to draw many conclusions regarding the reason that these injuries are increasing in number and cost. To our knowledge there have been no changes in how these injuries are diagnosed or treated during this period, and therefore any increases are likely due to behavioural or lifestyle changes in the population, but further studies are needed to address this issue. However, from this data, it is clear that the magnitude of these injuries signifies an urgent need for increased clinical recognition, alongside an improvement in our understanding, treatment and prevention of tendon and ligament injuries.

\section{Supplementary information}

Supplementary information accompanies this paper at https://doi.org/10 1186/s40621-020-0231-x.

Additional file 1. Copy of data received from ACC which was used for this study. Details of claim count per year, and cost of claims per year, broken down into anatomical site of injury, gender of claimant, ethnicity of claimant and age of claimant.

Additional file 2. Copy of Aotearoa/New Zealand population by prioritised ethnicity and age groups as of the 2013 census, received from Statistics NZ

Additional file 3. List of all tendon/ligament injury diagnoses included in the study

\section{Acknowledgements}

The authors would like to thank the New Zealand Accident Compensation Corporation System (ACC) for providing the data used in this study.

\section{Author contributions}

Design of study protocol: DM, DN, GG, JC, ND. Acquisition of study data: SC, DM, SJP.

Data analysis: SC, GG, SJP, DM. Interpretation of data: SC, MZ, ND, SJP, DM.

Drafting of manuscript: SC, DM. Final approval of manuscript: all authors.

\section{Funding}

This work was funded by the Auckland Medical Research Foundation (Dr Musson's Senior Research Fellowship), the Health Research Council of New Zealand (15/576), and a University of Auckland Summer Studentship (Ms
Clark). The funders took no part in the analyses nor the writing of this manuscript.

Availability of data and materials

All data generated or analysed during this study are included in this published article [and its supplementary information files].

Ethics approval and consent to participate

Not applicable.

\section{Consent for publication}

Not applicable.

\section{Competing interests}

The authors declare that they have no competing interests.

\section{Author details}

${ }^{1}$ Department of Medicine, University of Auckland, Auckland, New Zealand. ${ }^{2}$ Department of Orthopaedics, Auckland District Health Board, Auckland, New Zealand. ${ }^{3}$ Te Kupenga Hauora Māori, University of Auckland, Auckland, New Zealand. ${ }^{4}$ Department of Rheumatology, Auckland District Health Board, Auckland, New Zealand.

Received: 3 November 2019 Accepted: 3 January 2020

Published online: 10 February 2020

\section{References}

Albers IS, Zwerver J, Diercks RL, Dekker JH, Van den Akker-Scheek I. Incidence and prevalence of lower extremity tendinopathy in a Dutch general practice population: a cross sectional study. BMC Musculoskelet Disord. 2016;17:16.

Clayton RA, Court-Brown CM. The epidemiology of musculoskeletal tendinous and ligamentous injuries. Inj. 2008;39(12):1338-44.

Coghlan JA, Buchbinder R, Green S, Johnston RV, Bell SN. Surgery for rotator cuff disease. Cochrane Database Syst Rev. 2008;1:CD005619.

Colvin AC, Egorova N, Harrison AK, Moskowitz A, Flatow EL. National trends in rotator cuff repair. J Bone Joint Surg Am. 2012;94(3):227-33.

De Boer AS, Schepers T, Panneman MJ, Van Beeck EF, Van Lieshout EM. Health care consumption and costs due to foot and ankle injuries in the Netherlands, 1986-2010. BMC Musculoskelet Disord. 2014;15:128.

de Jong JP, Nguyen JT, Sonnema AJ, Nguyen EC, Amadio PC, Moran SL. The incidence of acute traumatic tendon injuries in the hand and wrist: a 10-year population-based study. Clin Orthop Surg. 2014;6(2):196-202.

Gianotti SM, Marshall SW, Hume PA, Bunt L. Incidence of anterior cruciate ligament injury and other knee ligament injuries: a national populationbased study. J Sci Med Sport. 2009;12(6):622-7.

Hopkins C, Fu SC, Chua E, Hu X, Rolf C, Mattila VM, et al. Critical review on the socio-economic impact of tendinopathy. Asia Pac J Sports Med Arthrosc Rehabil Technol. 2016;4:9-20.

Houshian S, Tscherning T, Riegels-Nielsen P. The epidemiology of Achilles tendon rupture in a Danish county. Inj. 1998;29(9):651-4.

James R, Kesturu G, Balian G, Chhabra AB. Tendon: biology, biomechanics, repair, growth factors, and evolving treatment options. J Hand Surg. 2008;33(1):102-12.

Jansen P BK, Crengle S. He Ritenga Whakaaro: Māori experiences of health services [internet]. Auckland: Mauri Ora Associates 2008.

Krug EG, Sharma GK, Lozano R. The global burden of injuries. Am J Public Health. 2000;90(4):523-6.

Kukkonen J, Joukainen A, Lehtinen J, Mattila KT, Tuominen EK, Kauko T, et al. Treatment of non-traumatic rotator cuff tears: a randomised controlled trial with one-year clinical results. Bone Joint J. 2014;96-B(1):75-81.

Lipman K, Wang C, Ting K, Soo C, Zheng Z. Tendinopathy: injury, repair, and current exploration. Drug Des Devel Ther. 2018;12:591-603.

Liu Y, Ramanath HS, Wang DA. Tendon tissue engineering using scaffold enhancing strategies. Trends Biotechnol. 2008;26(4):201-9.

Maher A, Leigh W, Brick M, Young S, Millar J, Walker C, et al. Gender, ethnicity and smoking affect pain and function in patients with rotator cuff tears. ANZ J Surg. 2017:87(9):704-8.

MinistryofHealth. HISO 10001:2017 Ethnicity Data Protocols. [Internet]. Wellington: Ministry of Health.2017.

Mock C, Cherian MN. The global burden of musculoskeletal injuries: challenges and solutions. Clin Orthop Relat Res. 2008;466(10):2306-16. 
Nyyssonen T, Luthje P, Kroger $\mathrm{H}$. The increasing incidence and difference in sex distribution of Achilles tendon rupture in Finland in 1987-1999. Scand J Surg. 2008;97(3):272-5.

Paloneva J, Lepola V, Aarimaa V, Joukainen A, Ylinen J, Mattila VM. Increasing incidence of rotator cuff repairs--a nationwide registry study in Finland. BMC Musculoskelet Disord. 2015;16:189.

Raikin SM, Garras DN, Krapchev PV. Achilles tendon injuries in a United States population. Foot Ankle Int. 2013;34(4):475-80.

Riley G. Tendinopathy-from basic science to treatment. Nat Clin Pract Rheumatol. 2008;4(2):82-9.

Sanders TL Jr, Maradit Kremers H, Bryan AJ, Ransom JE, Smith J, Morrey BF. The epidemiology and health care burden of tennis elbow: a population-based study. Am J Sports Med. 2015;43(5):1066-71.

Vitale MA, Vitale MG, Zivin JG, Braman JP, Bigliani LU, Flatow EL. Rotator cuff repair: an analysis of utility scores and cost-effectiveness. J Shoulder Elbow Surg [et al]2007;16(2):181-187.

Walker-Bone K, Palmer KT, Reading I, Coggon D, Cooper C. Occupation and epicondylitis: a population-based study. Rheumatol. 2012;51(2):305-10.

Zbrojkiewicz D, Vertullo C, Grayson JE. Increasing rates of anterior cruciate ligament reconstruction in young Australians, 2000-2015. Med J Aust. 2018; 208(8):354-8.

\section{Publisher's Note}

Springer Nature remains neutral with regard to jurisdictional claims in published maps and institutional affiliations.

Ready to submit your research? Choose BMC and benefit from:

- fast, convenient online submission

- thorough peer review by experienced researchers in your field

- rapid publication on acceptance

- support for research data, including large and complex data types

- gold Open Access which fosters wider collaboration and increased citations

- maximum visibility for your research: over $100 \mathrm{M}$ website views per year

At $\mathrm{BMC}$, research is always in progress.

Learn more biomedcentral.com/submissions 